\title{
CONSORCIOS MICROBIANOS: UNA METÁFORA BIOLÓGICA APLICADA A LA ASOCIATIVIDAD EMPRESARIAL EN CADENAS PRODUCTIVAS AGROPECUARIAS*
}

\author{
DIANA CAROLINA OCHOA CARREÑO"* \& ALEXANDRA MONTOYA RESTREPO \\ UNIVERSIDAD NACIONAL DE COLOMBIA
}

Recibido/ Received/ Recebido: 02/10/2010 - Aceptado/ Accepted / Aprovado: 29/11-2010

\begin{abstract}
Resumen
Este artículo ofrece una nueva visión del modelo de asociatividad empresarial en cadenas productivas agropecuarias, mediante la propuesta de la metáfora biológica de los consorcios microbianos. Recopila diversas aplicaciones de la metáfora como metodología para el estudio de las organizaciones y sus problemas, así como la naturaleza, características y fundamentos tanto de los consorcios microbianos como de los encadenamientos productivos agropecuarios. Se formula una metáfora entre estos dos campos del conocimiento, sobre la base de los principios de la teoría general de sistemas. El documento concluye exponiendo las ventajas y limitaciones de esta metodología conceptual para el caso de las cadenas productivas agropecuarias.
\end{abstract}

Palabras clave: Metáforas Organizacionales, Consorcios microbianos, Asociatividad empresarial

\section{MICROBIAL CONSORTIA: A BIOLOGICAL METAPHOR APPLIED TO ENTERPRISE ASSOCIATION IN AGRICULTURAL PRODUCTION CHAINS}

\begin{abstract}
This article provides a new view of Enterprise association model in agricultural production chains, through a biological metaphor proposal of microbial consortia. It collects various implementation cases of the metaphor as a methodology for organization study and their problems, as well as, nature, characteristics and fundaments of both microbial consortia and agricultural production chains. A metaphor is formulated between this two knowledge fields, based on the principles of general system theory. The document concludes exposing advantages and limitations of this conceptual methodology for agricultural production chains case.

Key words: Organizational metaphors, microbial consortia, Enterprise association.
\end{abstract}

Investigación realizada en el Marco de la Maestría de Administración de empresas, en el marco del proyecto de Investigación No. 11442 METÁFORAS BIOLÓGICAS Y ORGANIZACIÓN, Sistema de Información de la investigación HERMES, Universidad Nacional de Colombia.

" Microbióloga Industrial, Pontificia Universidad Javeriana. Magíster en Administración (C), Universidad Nacional de Colombia. E-mail: dicochoaca@unal.edu.co; diana8ac@yahoo.com

*** Doctora en Ciencias Económicas, Profesora Asociada, Facultad de Ciencias Económicas, Universidad Nacional de Colombia.

E-mail: lamontoyar@unal.edu.co. 


\title{
CONSÓRCIOS MICROBIANOS: UMA METÁFORA BIOLÓGICA APLICADA À ASSOCIATIVIDADEEMPRESARIALEMCADEIASPRODUCTIVASAGROPECUÁRIAS
}

\section{Resumo}

\begin{abstract}
Esteartigo oferece uma nova visão do modelo de associatividade empresarial emcadeias de produção agropecuária, através de uma proposta de metáfora biológica dos consórcios microbianos. Reúne diversas aplicações metodológicas da metáfora para o estudo das organizações e dos seus problemas, bemcomoda natureza, as característicase os fundamentos dos consórcios microbianose dascadeias de produção agrícola. Propõe-se uma metáfora entre esses dois campos do conhecimento, baseada nos princípios da teoria geral dos sistemas. O artigo conclui apresentando as vantagens e limitações desta abordagem conceitual no caso das cadeias de produção agropecuária.
\end{abstract}

Palavra chave: Metáforas organizacionais, consórcios microbianos, associatividade empresarial.

Ochoa, D. \& Montoya, A. (2010) Consorcios microbianos: una metáfora biológica aplicada a la asociatividad empresarial en cadenas productivas agropecuarias. En: Revista de la Facultad de Ciencias Económicas de la Universidad Militar Nueva Granada. rev.fac.cienc.econ, XVIII (2)

JEL: N56, M29

\section{Introducción}

Los crecientes avances científicos, el cambio tecnológico, la economía globalizada y el desarrollo industrial son elementos dinámicos que en el panorama mundial, están determinando la capacidad productiva y competitiva de los países, y provocando ajustes en el desarrollo de las relaciones comerciales entre éstos. Una de las estrategias empresariales más efectivas para operar ante tales condiciones, de manera exitosa y rentable, es la asociatividad empresarial; sin embargo, la aceptación, implementación y ejecución de este esquema no han sido satisfactorias debido, en parte, al desconocimiento, desconfianza y confusión que de él derivan (Montoya, 2010). Con el ánimo de superar esta y otras dificultades se acude a la metáfora biológica, la cual permite abordar el estudio de los encadenamientos productivos en el sector agropecuario, uno de los más vulnerables de los sectores productivos, a partir de los desarrollos conceptuales propios de las ciencias biológicas. Se destacan los aportes de la microbiología, que pone de manifiesto las ventajas de integrar diversos componentes y factores en los estudios ecológicos, para obtener una mejor comprensión del funcionamiento de los sistemas naturales (Guerrero, López \& Antón, 2005). La metáfora de los consorcios microbianos permite dilucidar principios claves para la consolidación de un modelo asociativo eficiente y sostenible, tal como ocurre en la naturaleza. El presente artículo inicia con una recopilación de varias de las principales metáforas biológicas aplicadas al estudio y comprensión de las organizaciones.

En seguida se identifican y analizan los principios y naturaleza de los consorcios microbianos. Posteriormente, se exponen los fundamentos y características del modelo de asociatividad empresarial en cadenas productivas agropecuarias y, finalmente, se presenta una nueva metáfora biológica desde una perspectiva conceptual.

\section{La metáfora biológica: una nueva visión de la organización}

Una competencia crítica que deben desarrollar directivos, gestores, líderes y profesionales en cualquier área del conocimiento, es la de "comprender" las situaciones, principios, contextos y demás variables que componen su objeto de estudio, aquello que están intentando organizar o gestionar. Aunque generalmente se acepta que esta competencia deriva de un proceso sicológico o intuitivo, aprendido por la experiencia y/o por una habilidad natural 
diferencial, filósofos como Wittgenstein (citado por Albano, 2006) afirman que el acto de "comprender" es esencialmente un procedimiento lingüístico, estimulado por la necesidad de resolver problemas, el cual permite al ser humano reconocer la naturaleza, lógica y significado de algo.

La relación que se establece entre lenguaje y comprensión puede ser explicada desde diferentes modelos teóricos, entre ellos, la Teoría de la Metáfora. Esta teoría, estudiada por George Lakoff, Mark Jonson \& Mark Turner (citados por Ramírez, 2006) permite entender cómo, en el proceso de comprensión, la experiencia se relaciona con el pensamiento para ser integrada al conocimiento, relación que el lenguaje, a su vez, pone de manifiesto a través de la metáfora. Según el diccionario de la Real Academia Española (2010), una metáfora es la:

"Aplicación de una palabra o de una expresión a un objeto o a un concepto, al cual no denota literalmente, con el fin de sugerir una comparación (con otro objeto o concepto) y facilitar su comprensión”.

Al utilizar una metáfora son dos o más ideas las que se asocian en la mente del emisor, en virtud de rasgos comunes que, para ese emisor, les confieren similitud o parecido, y que sirven para tender un puente entre dos dominios conceptuales que carecían de conexión (Boquera, 2005).

El análisis de la realidad organizacional ha sido siempre una tarea que presenta enormes retos y dificultades. La teoría organizacional se esfuerza por construir conceptos, categorías e hipótesis destinadas a describir, interpretar y, de ser posible, explicar la vida y funcionamiento de las organizaciones (Carrillo, 2003). Una aproximación metodológica que se ha mostrado fecunda para adelantar este trabajo es la de Morgan (1991) quien, en su libro Imágenes de la Organización, propone el uso de diferentes metáforas con el fin de explorar y comprender las organizaciones, de una manera distinta. Para este autor el uso de la metáfora implica no solo un:

"Modo de pensar y un modo de ver que traspasa el cómo se comprende el mundo en general".
Sino que también estimula el pensamiento creativo y disciplinado, proporciona nuevos métodos de formulación y resolución de problemas y, facilita el diseño y la gestión de organizaciones de un modo que no había sido pensado antes.

Morgan (1991), señala diferentes metáforas en el estudio de las organizaciones:

- La organización como cerebro, que se enfoca en la importancia del procesamiento de la información, el aprendizaje y la inteligencia.

- La organización como cultura, que es vista como la residencia de ideas, valores, normas, rituales y creencias que sostienen la realidad social.

- La metáfora política, que se enfoca en los diferentes conjuntos de intereses, de conflictos y de juegos potenciales que configuran las actividades organizacionales.

- La organización como una "prisión psíquica", que ve a las personas atrapadas por sus propios pensamientos, ideas y creencias o por preocupaciones originadas en la parte inconsciente de la mente.

- La organización como un instrumento de dominación, que "utiliza" a sus empleados y los bienes nacionales y mundiales para conseguir sus propios fines.

- La organización vista como un flujo de cambio y transformación.

Finalmente, se destaca la visión ortodoxa basada en las metáforas de la organización como máquina y como organismo. La metáfora de la máquina es subsidiaria del trabajo de dos teóricos gerenciales clásicos, Frederick Taylor \& Henry Fayol, y sostiene el desarrollo de la organización burocrática de Max Weber. Se enfoca en el diseño y gestión de las organizaciones como elementos de relojería, donde cada parte tiene definido claramente su rol dentro de la función del conjunto. En tales organizaciones se espera que los empleados se comporten como piezas de una máquina y que la operación sea rutinaria, eficiente, exacta y predecible. Por otro lado, la visión de las organizaciones como organismos es una metáfora que centra su atención en la comprensión y gestión de las necesidades organizacionales y las relaciones con el entorno, pensando en ellas como sistemas vivos. 
Este enfoque es una aplicación de la Teoría General de Sistemas (TGS), cuyos conceptos básicos fueron desarrollados por el biólogo Ludwing von Bertalanffy, la cual pone de relieve la imagen de los organismos vivos como totalidades integradas. Es, en sí misma, un nuevo paradigma, una visión "ecológica" que reconoce la interdependencia fundamental entre todos los fenómenos y entre ellos y la naturaleza (Capra, 1998). Dicha relación analógica entre biología y gestión organizacional es el origen de la Metáfora Biológica:

\section{"La ley natural se invoca para legitimi- zar las organizaciones de la sociedad" (Morgan, 1991, 64).}

Bajo esta nueva visión, las organizaciones son "Sistemas de Aproximación", es decir, sistemas abiertos que intercambian energía y materia con su entorno, en una convivencia dada por la interacción y dependencia mutua. Tal enfoque permite concebir la organización como un conjunto de conjuntos interactivos o subsistemas, cuyas interrelaciones ponen de manifiesto diferentes variables que influyen en su funcionamiento.

\section{Aplicación de la metáfora biológica en el campo de la gestión}

González \& Llinás (2004), entre otros autores, han reconocido fuertes transformaciones en las imágenes de la ciencia, ocurridas en el transcurso del siglo XX, debido a una apertura epistemológica provocada por las disciplinas biológicas, las cuales han proporcionado nuevos esquemas explicativos superadores del modelo positivista, anti historicista y formalista, en muchos dominios del conocimiento. Muestra de ello es el surgimiento de disciplinas como la "Economía Ecológica", la cual ofrece un marco de estudio para comprender las dinámicas y conflictos distributivos que se generan en la sociedad contemporánea, derivados de la crisis ambiental actual. Para García-Frapolli \& Toledo (2008), la contribución más sólida de esta disciplina ha sido su capacidad para integrar, de manera amplia y abierta, elementos centrales de la economía, ecología, termodinámica, ética, política, y muchas otras disciplinas provenientes de las ciencias sociales y naturales, en aras de desarrollar una perspectiva más integrada sobre las interacciones entre las sociedades humanas y los ecosistemas.
El concepto de "Co-evolución", que describe los cambios genéticos de unas especies como respuesta a la evolución de otras, ha tenido una extensa aplicación en áreas de investigación de perfil socio-económico, biológico y tecnológico, en las cuales se percibe como la transferencia de información y patrones de comportamiento, y ha llevado a considerar que existe una inevitable interdependencia entre las tecnologías, las instituciones, los valores y el bio-ambiente físico, estrechando una relación entre la eco-innovación, los sistemas gerenciales sustentables y las tecnologías verdes (Rammel, Stagl \& Wilfing, 2007). Términos como "nicho", "tasa de nacimiento", "tasa de mortalidad", "disponibilidad de recursos", "evolución", "extinción", "selección", "variación", "retención", etc., han sido ampliamente usados para describir y explicar las circunstancias ambientales que comparten las organizaciones. Hannan \& Freeman (citados por Ahumada, 2002), principales representantes de esta perspectiva evolutiva-ecológica, explican que las organizaciones compiten por recursos escasos en un entorno que selecciona a aquellas que cuentan con más y mejores capacidades para hacer frente a sus demandas, eliminando a las menos competentes. Todos estos aportes obligan a pensar en una gerencia capaz de diseñar e implementar un modelo de vida basado en preceptos socio-ecológicos de largo plazo, reconociendo y aceptando la interdependencia existente entre variables de alta complejidad, tales como las instituciones, el medio ambiente dinámico, los procesos económicos, las tecnologías disponibles y los factores culturales, entre otros.

Según Capra (1998) hay diversas soluciones, algunas muy sencillas, para los principales problemas de las organizaciones, que garantizan su supervivencia y sostenibilidad, pero que:

\section{"Requieren un cambio radical en nuestra percepción y pensamiento".}

La Metáfora Biológica hace posible esa nueva percepción, por cuanto permite aplicar el conocimiento e información proporcionados por las ciencias naturales, a la creación y desarrollo de estructuras sociales y organizacionales productivas, sostenibles y exitosas en el tiempo. En su investigación, Montoya $(1999,2010)$ subraya la importancia de las 
metáforas biológicas en la gestión, ámbito en donde se pretende emular el sistema perfecto de la natu- raleza, la autora destaca diferentes aspectos que se pueden ver en la Tabla 1.

Tabla 1. Metáforas biológicas aplicadas a la gestión de organizaciones ${ }^{1}$

\begin{tabular}{|c|c|c|}
\hline \multicolumn{3}{|c|}{ METÁFORAS BIOLÓGICAS APLICADAS A LA GESTIÓN DE ORGANIZACIONES } \\
\hline AUTOR & $\begin{array}{l}\text { METÁFORA } \\
\text { BIOLÓGICA }\end{array}$ & DESCRIPCIÓN \\
\hline Stafford Beer & $\begin{array}{l}\text { "Abecedario de la } \\
\text { Administración" }\end{array}$ & $\begin{array}{l}\text { Esta idea se basa en la conceptualización de términos clave para explicar la admi- } \\
\text { nistración en expresiones más biológicas. Acústica, Biología, Cibernética, Demografía, } \\
\text { Ingeniería (Engenieering), Fluidos y Genética son algunos de los aspectos en los que } \\
\text { enfatiza este autor para explicar la forma de adaptación de las organizaciones a sus } \\
\text { diferentes entornos, específicamente el del medio ambiente. }\end{array}$ \\
\hline Stafford Beer & $\begin{array}{l}\text { La organización como } \\
\text { un "Sistema Viable" }\end{array}$ & $\begin{array}{l}\text { Es una aplicación de los conceptos de la cibernética para desarrollar un modelo que } \\
\text { refleja la estructura, actividades, interrelaciones y flujos de información en las organi- } \\
\text { zaciones sociales, haciendo una analogía con el sistema nervioso del cuerpo humano. } \\
\text { Este sistema lo que hace es permitir a las organizaciones obtener las flexibilidad que } \\
\text { necesitan para sobrevivir en medios ambientes rápidamente cambiantes y complejos. }\end{array}$ \\
\hline Eduardo Illera & $\begin{array}{l}\text { La organización como } \\
\text { un "Sistema Humano" }\end{array}$ & $\begin{array}{l}\text { Establece una relación entre los sistemas constitutivos del cuerpo humano con los de } \\
\text { la organización, destacando: } \\
\text { Estructura o Sistema de Sostén, Sistema de Coordinación Central, Sistema de Circula- } \\
\text { ción, Sistema de Nutrición, Sistema de Coordinación Central }\end{array}$ \\
\hline $\begin{array}{l}\text { Francis } \\
\text { Fukuyama }\end{array}$ & $\begin{array}{l}\text { La organización como } \\
\text { "Relaciones de Con- } \\
\text { fianza" }\end{array}$ & $\begin{array}{l}\text { La condición de una estructura organizacional o incluso de un sistema, depende de que las } \\
\text { relaciones establecidas en su interior operen fluidamente, siempre y cuando cada una de } \\
\text { las partes haga el 100\% de lo que le corresponde dentro de la supervivencia del sistema. }\end{array}$ \\
\hline $\begin{array}{l}\text { Ronnie } \\
\text { Lessem }\end{array}$ & $\begin{array}{l}\text { "El Árbol del Conoci- } \\
\text { miento en la Adminis- } \\
\text { tración" }\end{array}$ & $\begin{array}{l}\text { El proceso de conocimiento se describe en la imagen de un árbol: el suelo es como la } \\
\text { atmósfera que le da el enriquecimiento cultural en particular; las raíces dan el sosteni- } \\
\text { miento teórico al tallo, que debe ser visible, claro, firme y coherente; sus ramas mues- } \\
\text { tran las diferentes teorías, las cuales se extienden desde el tallo para cada aplicación, y } \\
\text { sus frutos representan los ejemplos de caso. }\end{array}$ \\
\hline Peter Senge & $\begin{array}{l}\text { Metáfora del "Sistema } \\
\text { Inmunológico" }\end{array}$ & $\begin{array}{l}\text { La analogía con la organización se basa en la capacidad y flexibilidad de actuar frente } \\
\text { a cambios en el medio ambiente. La esencia del control orgánico es la capacidad para } \\
\text { conservar equilibrios internos cruciales para la estabilidad y el crecimiento. }\end{array}$ \\
\hline $\begin{array}{l}\text { Luis Arturo } \\
\text { Rivas }\end{array}$ & $\begin{array}{l}\text { "La Organización } \\
\text { Celular" }\end{array}$ & $\begin{array}{l}\text { Una célula es un ser vivo que posee las principales características de la vida, y puede } \\
\text { actuar tanto de manera independiente como en concurso con otras células, para dar ori- } \\
\text { gen a un ser más complejo y superior. La metáfora parte de la idea que en una organiza- } \\
\text { ción celular existen grupos autodirigidos o unidades autónomas que pueden operar tan- } \\
\text { to solas, como en conjunción con otras, para crear mecanismos de negocio superiores. }\end{array}$ \\
\hline Gunter Pauli & $\begin{array}{l}\text { "Gerencia } \\
\text { Inmunológica" }\end{array}$ & $\begin{array}{l}\text { El sistema inmunológico ofrece la mejor inspiración para las prácticas gerenciales que se } \\
\text { requiere que hoy triunfen a largo plazo. Es altamente descentralizado, sabe atacar proble- } \\
\text { mas locales sin que se le pida intervención, no solicita aprobación de un tomador de de- } \\
\text { cisiones de nivel superior, es el mejor modelo de auto-organización y de empowerment. }\end{array}$ \\
\hline $\begin{array}{l}\text { Alexandra } \\
\text { Montoya }\end{array}$ & "Gerencia Genética" & $\begin{array}{l}\text { El sistema genético en los seres vivos cuenta con características similares a los siste- } \\
\text { mas de información gerencial en una organización. La gerencia genética se plantea } \\
\text { como una comparación basada en el entendimiento de las propiedades del ADN, y } \\
\text { la forma en que se transmite la información dentro de cada cadena, con los procesos } \\
\text { implementados en las sociedades actuales necesitadas de conocimiento y de grandes } \\
\text { cantidades de información procesada a favor del sostenimiento de las mismas. }\end{array}$ \\
\hline
\end{tabular}

1 Adaptado de Montoya (1999, 2010). 
Una de las principales ventajas de la metáfora biológica es su contribución al entendimiento de las relaciones organización- ambiente. Al enfatizar en las necesidades de supervivencia de la organización, mejora su gestión pues se enfoca en el objetivo principal (misión) y busca el equilibrio de los subsistemas (estratégico, estructural, tecnológico, humano y de dirección) entre sí y con su entorno. Alerta sobre el hecho de que para organizar existe una variedad de opciones, y muestra que la organización efectiva depende de las circunstancias del entorno. Con su aporte ecologista refuerza la necesidad de una teoría de las relaciones interorganizacionales para tratar con entornos complejos, lo cual, a su vez, posibilita la generación de procesos de innovación. Sin embargo, Cabello (2000) recalca, como dificultades de la misma, que la metáfora biológica mira las organizaciones y a su entorno en forma demasiado concreta, desconociendo su calidad de fenómenos sociales y, por tanto, el que son producto de la creatividad humana; esto conduce a ver a la política y los conflictos como anormales y disfuncionales. Además, muchas organizaciones no están unificadas funcionalmente como los organismos; los diferentes elementos de una organización generalmente son capaces de vivir su vida separadamente, cosa que a menudo hacen. No identifica las variables internas que afectan la administración, ni la influencia de los grupos o las instituciones del medio ambiente sobre el desempeño de la organización y, finalmente, como con otras metáforas, corre el peligro de que se convierta en una ideología (Morgan, 1991).

\section{Biología de los consorcios microbianos: naturaleza y principios}

La microbiología, como ciencia biológica básica, ha suministrado algunas de las herramientas de investigación más versátiles para determinar la naturaleza de los procesos característicos de la vida en sus diversas formas. Entre otros aspectos, esta ciencia se ocupa de cómo el conocimiento de los microorganismos, un extenso y variado grupo de organismos microscópicos, puede ayudar a comprender mejor la biología de los organismos superiores, incluido el hombre. A diferencia de las células de animales y plantas, las células microbianas pueden vivir aisladas en la naturaleza. Una célula microbiana aislada es, en general, capaz de llevar a cabo sus procesos vitales de crecimiento, generación de energía y reproducción, independientemente de otras células de la misma o de diferente especie. Sin embargo, en la naturaleza, las células microbianas rara vez viven solas; su estrategia de supervivencia es la agrupación.

"Las células individuales forman poblaciones; las poblaciones que utilizan los mismos recursos constituyen agrupaciones llamadas "gremios", y los conjuntos de gremios que llevan a cabo procesos fisiológicos complementarios interaccionan para formar comunidades microbianas. Estas comunidades interactúan, a su vez, con comunidades de macroorganismos y definen el conjunto del ecosistema" (Madigan, Martinko \& Parker, 1999, 533).

A lo largo de más de tres mil millones de años de evolución, los ecosistemas del planeta se han organizado en formas sutiles y complejas para maximizar su sostenibilidad; la vida sobre la Tierra ha sido posible gracias a combinaciones cada vez más complejas de cooperación y coevolución. La asociación -tendencia a asociarse, establecer vínculos, vivir unos dentro de otros y cooperar- es una de las características distintivas de la vida (Capra, 1998).

"La vida no conquistó el globo con combates, sino con alianzas" (Margulis \& Sagan, 1986, 15, citado por Capra, 1998, 242).

Un Consorcio Microbiano es una asociación natural de dos o más poblaciones microbianas, de diferentes especies, que actúan conjuntamente como una comunidad en un sistema complejo, donde todos se benefician de las actividades de los demás. La asociación refleja estilos de vida sinérgicos o sintróficos (que significa "comiendo juntos") en el que el crecimiento y el flujo cíclico de nutrientes se conduce más efectiva y eficientemente que en poblaciones individuales (López, Domínguez \& García, 2007). Funcionalmente, un consorcio microbiano supera la suma de sus partes; sus miembros mantienen la compatibilidad metabólica y ecológica siempre y 
cuando las transformaciones ambientales que se generan permitan que ellos coexistan cercanamente.

Un consorcio microbiano puede desempeñar funciones complicadas que poblaciones individuales no podrían; además, la vida en asociación puede generar mayor resistencia a las fluctuaciones del ambiente y promover la estabilidad de los miembros, en el tiempo. Estos rasgos distintivos dependen de dos características. Primero, los miembros de un consorcio se comunican el uno con el otro. Ya sea por el intercambio de sustancias o por señales moleculares, cada población detecta y responde a la presencia de otras dentro del consorcio, ejerciendo sobre ellas un control positivo o negativo en su crecimiento y/o metabolismo. Aquí, "comunicación" se refiere a interacciones físico-químicas en las cuales el emisor, el canal y el receptor de la información están identificados. Esta comunicación permite la segunda característica importante, la división del trabajo. La producción total de un consorcio depende de la combinación de tareas desempeñadas por los constituyentes individuales, es decir, por las poblaciones microbianas involucradas. Otra importante característica de los consorcios es su habilidad para desempeñar funciones que requieren múltiples pasos. Tales tareas son posibles cuando los diferentes pasos se completan, mediante especies microbianas especializadas (Brener, You \& Arnold, 2008), como se puede ver en la llustración 1.

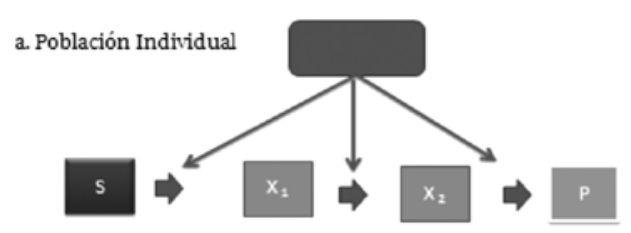

b. Consorcio

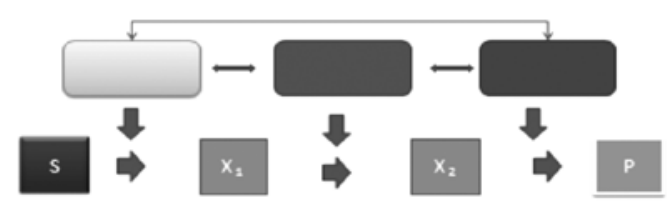

Ilustración 1. Procesamiento de reacciones complejas por (a) una población individual o (b) un consorcio microbiano $^{2}$

2 Adaptación de las autoras.
La generación de un producto $(\mathrm{P})$ puede requerir de múltiples pasos para convertir el sustrato (S), a través de la síntesis secuencial de intermediarios (X1 y X2). (a) Una población individual es responsable de la síntesis de todas las enzimas necesarias para llevar a cabo las reacciones intermedias. (b) Cada población está dedicada a un solo paso.

Las reacciones desempeñadas por cada población pueden coordinarse por la comunicación intercelular. Un consorcio microbiano como el que se ilustra en (b) tiene dos ventajas potenciales. Primero, limita el número de elementos externos en cada población, lo cual protege de un desequilibrio metabólico. Tal desequilibrio, con frecuencia, deriva en un retardo del crecimiento y en una baja producción. Segundo, la división del trabajo simplificará la optimización de cada reacción en la conversión, mediante la especialización de la maquinaria bioquímica de cada población (Brener, You \& Arnold, 2008, 484).

Los consorcios microbianos pueden resistir mejor los periodos de limitación de nutrientes debido a la diversidad metabólica disponible por la diversidad de especies, combinada con la habilidad de compartir metabolitos dentro de la comunidad. Una población minoritaria puede llegar a ser la más activa en un periodo de limitación de nutrientes si tiene la habilidad metabólica capaz de sostener la supervivencia de todo el consorcio. De hecho, el consorcio contiene unas especies minoritarias las cuales han sido retenidas por selección natural para responder a tal situación (Maier, Pepper \& Gerba, 2009). Es importante destacar que ante niveles muy bajos de algún nutriente o recurso, los microorganismos no pueden disponer de las cantidades adecuadas para su metabolismo; $y$, ante niveles muy altos, esos nutrientes $y / o$ recursos pueden causar toxicidad $e$ inhibir el crecimiento. Ante tales fluctuaciones, los consorcios activan sus controles homeostáticos, es decir, reacciones bioquímicas que le permiten al sistema retornar a su equilibrio vital.

Los consorcios microbianos también se han caracterizado en función del uso de los recursos. Muchas 
especies, comúnmente, se encuentran juntas porque tienen los mismos requerimientos ambientales y comparten elementos de su nicho, o porque dependen de la presencia de un factor común para su estrategia de vida. Normalmente el lugar geográfico en el que se ubica el consorcio, coincide con espacios en donde las condiciones ambientales son las óptimas, es decir, donde los microorganismos experimentan el mayor crecimiento y reproducción. Sin embargo, bajo condiciones extremas y para asegurar su supervivencia, pueden desarrollar estrategias como la Adaptación y la Mutación (Morris \& Blackwood, 2007). La adaptación ocurre cuando un cambio en el ambiente induce la expresión de un rasgo alternativo no heredable, (ej. modificación de elementos constituyentes y/o de la organización estructural) lo que proporciona a los microorganismos la capacidad para ajustarse a las nuevas condiciones. La adaptación está limitada por la constitución genética; solo los microorganismos que tengan el mejor genotipo pueden sobrevivir. Una mutación es un cambio heredable del genotipo, que causa un cambio permanente del individuo, llamado mutante. $\mathrm{Si}$ es capaz de prosperar bajo las condiciones ambientales de su entorno, el mutante se perpetuará, de lo contrario perecerá. La mutación se puede producir de manera espontánea o por transferencia genética con otros microorganismos mediante los procesos de transformación, transducción o conjugación (Ilustración 2).

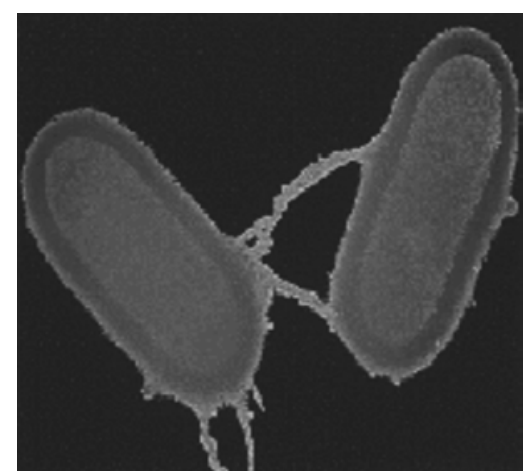

Ilustración 2. Microfotografía electrónica en la que se muestra la transferencia de material genético por conjugación, entre dos bacterias ${ }^{3}$

3 Fotografía aportada por los autores.
La célula donadora establece contacto con la receptora mediante un apéndice filamentoso llamado "Pili"; se forma un puente (poro) entre las dos células facilitando la transferencia (Escobar, 2009). La naturaleza y gran magnitud de las actividades metabólicas de los microorganismos en un consorcio propician importantes cambios en el ambiente: transformación de sustratos, agotamiento de recursos, elaboración de productos y eliminación de desechos, los cuales llegan a ser el sustrato para nuevos procesos bioquímicos, dando continuidad al flujo de materia y energía. En vez de competir por el mismo nutriente, los microorganismos del consorcio colaboran para llevar a cabo una transformación determinada que ninguna de las especies que intervienen en el proceso podrían realizar por sí misma; dicha transformación no puede determinarse recopilando las propiedades bioquímicas de cada especie de manera aislada. Los consorcios microbianos intervienen activamente en los ciclos biogeoquímicos y en muchos casos son los únicos agentes biológicos capaces de regenerar un recurso, haciéndolo disponible para el uso de otros microorganismos y organismos superiores. Un ciclo biogeoquímico es la transformación sucesiva de un elemento químico (C, N, S, P, Fe, etc.) efectuada por diversos agentes bióticos y abióticos, en la que se producen formas aprovechables del mismo, necesarias para el crecimiento y la reproducción de los seres vivos (Plante, 2007).

Dos ejemplos prácticos que demuestran la influencia de los consorcios microbianos en la actividad humana, específicamente en la producción agrícola $y$ en las explotaciones ganaderas, son el ciclo del nitrógeno en el suelo y el ecosistema del rumen. El nitrógeno $(\mathrm{N})$ es el macronutriente más importante para las plantas; ningún otro elemento químico esencial tiene tantas transformaciones, mediadas por microorganismos, como éste. El nitrógeno gaseoso $\left(\mathrm{N}_{2}\right)$ es el más abundante en la atmósfera terrestre; sin embargo no está disponible para el uso de las plantas. Para que éstas puedan aprovecharlo el $\mathrm{N}_{2}$ tiene primero que ser convertido en una forma química asimilable por las raíces, lo cual ocurre por la intervención sucesiva de poblaciones bacte- 
rianas, en el proceso conocido como nitrificación. Algunos microorganismos en el suelo pueden usar el nitrógeno como se encuentra disponible para la obtención de energía, convirtiéndolo $\mathrm{N}_{2}$ en el proceso de desnitrificación (Luo \& Zhou, 2006). Ya que estos productos son todos gaseosos son eliminados al ambiente permitiendo así la continuidad del ciclo (Ilustración 3).

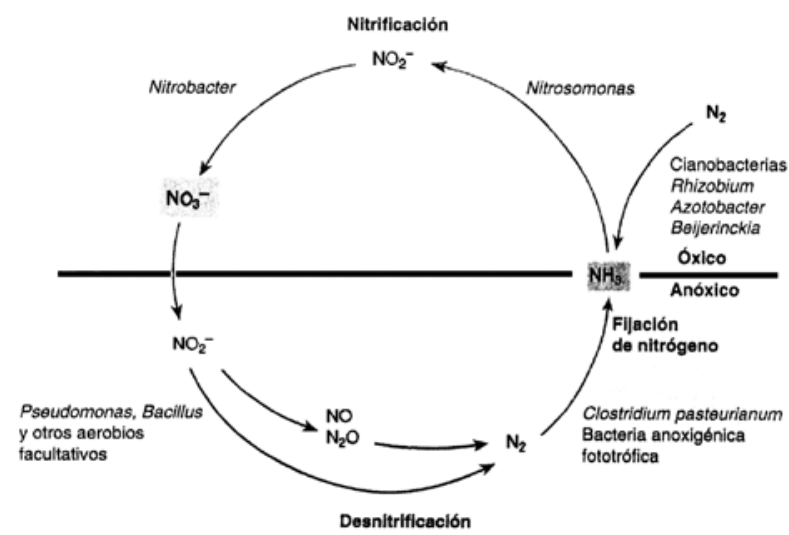

Ilustración 3. Ciclo de oxidación-reducción del nitrógeno ${ }^{4}$

En la mayoría de ecosistemas terrestres el Nitrógeno limita el crecimiento de los cultivos y, por lo tanto, el rendimiento neto de la producción agrícola. La deficiencia de este en plantas disminuye el tamaño de las hojas y reduce la producción de clorofila causando clorosis (hojas de color amarillo); el tamaño y la carnosidad de los frutos se ven igualmente disminuidos (Germinia, 2010). Esto puede contrarrestarse gracias a la capacidad de los consorcios microbianos propios del suelo para transformar el Nitrógeno en formas que son asimilables por las plantas. (McGill, 2007).

Los rumiantes son mamíferos herbívoros que poseen un órgano especial, el rumen, en cuyo interior se lleva a cabo la digestión de la hierba y plantas con hojas que consumen, mediante la actividad combinada de poblaciones microbianas especiales ya que ellos, en sí mismos, no producen las enzimas para dicho proceso. Algunos de los animales domésticos más importantes como las vacas, las ovejas y las cabras, son rumiantes. Dado que la alimentación humana depende en gran manera de estos animales, la microbiología del rumen tiene un significado económico considerable. El alimento permanece en el rumen de nueve a doce horas. Durante este tiempo las bacterias hidrolizan la celulosa, el almidón y otras fibras obteniendo glucosa libre. La glucosa pasa por una fermentación bacteriana en la que se producen ácidos grasos volátiles (AGV); éstos atraviesan la pared del rumen y pasan a la sangre. Desde allí van a los tejidos donde son oxidados por las células, que los utilizan como principal fuente de energía. Además de sus funciones digestivas, los microorganismos del rumen constituyen la principal fuente de nutrientes esenciales, proteínas y vitaminas, para el animal.

\section{Asociatividad empresarial en cadenas productivas agropecuarias: una estrategias de competitividad}

Colombia lleva más de una década inserta en un esquema económico mundial caracterizado por relaciones económicas más abiertas entre los diferentes países. Esta dinámica ha transformado los flujos de comercio entre el país y el resto del mundo, pero al mismo tiempo, lo han enfrentado a modelos de competencia sofisticados y complejos. Para el Estado resulta demasiado costoso dirigir instrumentos y políticas de apoyo a unidades productivas de manera individual, ya que los resultados en términos de valor agregado, competitividad y calidad de vida de los beneficiarios se diluye en el proceso (Valencia \& Muñoz, 2005). Por estas y otras razones, como la entrada en vigencia de tratados de libre comercio, la competitividad de países como Colombia debe pasar por la construcción de sistemas productivos asociativos, bien sea a través de redes empresariales, cadenas productivas, clústeres, distritos industriales, cooperativas o la modalidad más adecuada según las necesidades de cada caso, como una estrategia de competitividad para obtener una posición ventajosa y sostenible en el mercado.

4 Fuente. Madigan, Martinko \& Parker, 1999, 571. 
Según Rosales (citado por Narváez, Fernández \& Senior, 2008), la asociatividad es un mecanismo de cooperación interempresarial en el que cada una de las empresas involucradas mantiene su independencia jurídica y su autonomía gerencial, decidiendo voluntariamente su participación en un esfuerzo conjunto con las demás, para la búsqueda de un objetivo común. La opción de conformar cadenas productivas, como modelo de asociatividad empresarial, es la más antigua de las estrategias económicas colectivas conocidas. Esto es porque las empresas, aún las más solventes, poseen una autosuficiencia relativa puesto que, en mayor o menor medida, requieren enlazarse y desarrollar acuerdos con quienes proveen los bienes y servicios necesarios para el negocio, como materias primas, transporte, información, conocimiento, tecnología, regulación, dinero, comunicación, comercialización, entre otros (Kairuz, 2005).

En Colombia, el Ministerio de Agricultura y Desarrollo Rural a través del programa de cadenas productivas agropecuarias, trabaja estratégicamente en la armonización de las acciones de todos los agentes involucrados en la producción, transformación y distribución de productos agropecuarios, basado en el desarrollo de espacios de concertación entre el sector público y privado, que promuevan e impulsen mayores niveles de competitividad tanto en los escenarios internacionales como en los propios mercados internos. El sector tiene como política especializarse en especies estratégicamente cercanas al mercado internacional, concentrarse en zonas geográficas con condiciones óptimas para producirlas (núcleos productivos estratégicos), promover la generación de economías de escala, asociar capitales para viabilizarlas y, finalmente, hacer un uso creciente de tecnologías limpias. (Instituto Colombiano Agropecuario, 2003). El país debe potencializar las grandes ventajas comparativas con que cuenta para la producción agropecuaria y desarrollar ventajas competitivas que, en un marco de políticas públicas adecuado, disminuyan el riesgo y la incertidumbre asociadas a las actividades agropecuarias, y permitan el aprovechamiento de las oportunidades que se derivan de las nuevas tendencias en los mercados agroalimentarios mundiales (Peña, Nieto \& Díaz, 2008).
El modelo asociativo en cadenas productivas agropecuarias (Ilustración 4) supone una visión empresarial y una articulación al mercado. La visión empresarial implica entender la actividad agropecuaria como una empresa que se propone un objetivo económico, es decir, generar una ganancia, lo cual supone profesionalizar dicha actividad para que sea más eficiente y pueda alcanzar una relación costo/ beneficio favorable.

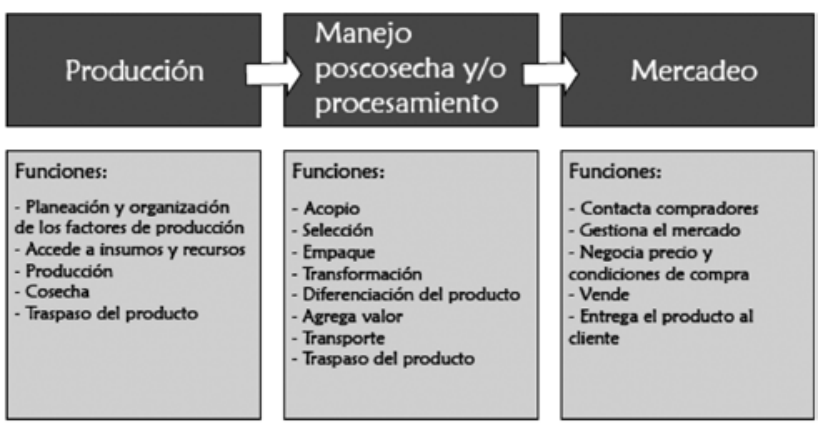

Ilustración 4. Representación esquemática de una cadena productiva agropecuaria ${ }^{5}$

La articulación al mercado consiste en planificar las opciones productivas con un claro y definido horizonte de mercado, esto es, con el propósito de generar y ofertar productos que demandan los consumidores y sean rentables, en un marco de relaciones que tengan, en lo posible, grados crecientes de formalidad (CENTA, 2002). Algunas de las ventajas más significativas que ofrece este modelo son:

- Amplía las economías de escala y por esta vía, permite alcanzar nuevos mercados, reducir costos y acceder a nuevas tecnologías.

- Acelera procesos de aprendizaje y estimula la innovación y la diferenciación.

- Permite la especialización en las etapas del proceso productivo en las que se cuenta con mayores ventajas competitivas.

- Aumenta el poder de negociación con clientes y proveedores.

- Alcanza objetivos comunes de mediano y largo plazo, orientados al desarrollo de la competitividad.

5 Fuente: CIAT, 2004, 10. 
- Facilita el procesamiento y agregación de valor a los productos.

- Permite el acceso a servicios de apoyo que resultan inaccesibles de manera individual (financieros, capacitación, estudios de mercado y logística).

- Resalta la distribución y el mercadeo como componentes importantes del costo final y factores claves de competitividad.

- Facilita la identificación y análisis del flujo de información.

- Permite analizar, de manera independiente $e$ interrelacionada, las diferentes actividades del proceso de producción, procesamiento y distribución identificando posibilidades de mejora en cada uno de los eslabones.

- Puede servir de puente integrador entre el medio rural y otros sectores económicos, para incrementar la contribución de las actividades agropecuarias en la disminución de la pobreza y del desempleo en el campo (Ministerio de Comercio, Industria y Turismo, 2009 y Acosta 2006).
El concepto de asociatividad en cadenas productivas agropecuarias parece muy sencillo, pero su puesta en marcha es muy compleja debido al fuerte componente cultural. Se nutre de un ingrediente esencial: la confianza; es decir, su éxito depende de la capacidad y las acciones deliberadas que emprendan los actores involucrados para construir capital social, entendido como el espíritu de cooperación que permita desarrollar procesos para la consecución de fines comunes. La capacidad asociativa y por ende las cadenas productivas agropecuarias no se generan espontáneamente; por el contrario, son una construcción social concertada que ha de formarse de manera sostenida, paso a paso, en medio de procesos muy complejos a nivel educativo, ambiental y en la formación de empresariado, entre otros. Desde la experiencia y el análisis de diversos casos se han identificado varios factores para el éxito de este modelo (Tabla 2).

Tabla 2. Factores de éxito en las cadenas productivas agropecuarias ${ }^{6}$

\begin{tabular}{|c|c|}
\hline \multicolumn{2}{|c|}{ FACTORES DE ÉXITO EN LAS CADENAS PRODUCTIVAS AGROPECUARIAS } \\
\hline UN BUEN ARTICULADOR O GESTOR & $\begin{array}{l}\text { Debe tener amplio conocimiento sobre el negocio en su integridad, habilidad de análisis, co- } \\
\text { municación, liderazgo, capacidad de desencadenar procesos colectivos, voluntad de ayuda, } \\
\text { negociación positiva, ética y persistencia en la búsqueda de metas, entre otras cualidades. }\end{array}$ \\
\hline $\begin{array}{l}\text { PARTICIPACIÓN DE MÍNIMO UN EM- } \\
\text { PRESARIO LIIDER }\end{array}$ & $\begin{array}{l}\text { Bien informado, animador del proceso, convencido de los beneficios del trabajo en ca- } \\
\text { dena, capaz de mostrar en su propio negocio ejemplos reales de trabajo en eslabona- } \\
\text { miento con los demás actores. }\end{array}$ \\
\hline POLÍTICAS PÚBLICAS & $\begin{array}{l}\text { Claras, equitativas, consistentes y apoyadas efectivamente por las instituciones y sus } \\
\text { agentes en las regiones. }\end{array}$ \\
\hline $\begin{array}{l}\text { INFORMACIÓN OBJETIVA, } \\
\text { CONFIABLE Y VÁLIDA }\end{array}$ & $\begin{array}{l}\text { Que permita mantener actualizado el diagnóstico de la cadena, su entorno y su funcio- } \\
\text { namiento interno. }\end{array}$ \\
\hline UN PLAN DE ACCIÓN & $\begin{array}{l}\text { Planteamiento estratégico con una visión de largo plazo pero que permita también alcan- } \\
\text { zar resultados mediante proyectos de mediano y corto plazo, capaces de mantener la } \\
\text { credibilidad del los procesos. }\end{array}$ \\
\hline FORMALIZACIÓN DE LOS VÍNCULOS & $\begin{array}{l}\text { Entre los actores debe haber acompañamiento y educación en las formas modernas de } \\
\text { negociar, trátese de proveedurías, compras anticipadas de cosechas, maquilas, produc- } \\
\text { ción y acopio cooperados, etc. }\end{array}$ \\
\hline MONITOREO & $\begin{array}{l}\text { Seguimiento a los acuerdos mediante indicadores de impacto, de efecto o de producto } \\
\text { que visibilicen resultados parciales y permitan mantener animados los procesos. }\end{array}$ \\
\hline REGLAS DEL JUEGO CLARAS & $\begin{array}{l}\text { Todos los involucrados deben saber cuál es el compromiso de cada quien y, con un } \\
\text { buen margen de certeza, conocer lo que van a ganar o lo que pueden perder. }\end{array}$ \\
\hline $\begin{array}{l}\text { VISIBILIZACIÓN DE TODO EL } \\
\text { PROCESO }\end{array}$ & s y resultados obtenidos. \\
\hline
\end{tabular}

6 Adaptado de Kairuz, 2005, 20-22. 
Una cadena productiva agropecuaria debe gestionarse como una cadena de valor, es decir, como:

"Una relación entre un conjunto de actores, en función de un producto específico, para agregar o aumentar su valor a lo largo de los diferentes eslabones" (Peña, Nieto \& Díaz, 2008, 78).

Ya que así se constituye en una conveniente herramienta para que el sector agropecuario pueda competir en el dinámico y exigente mercado globalizado y asumir varios de sus retos más importantes como la disminución de la pobreza, la inseguridad alimentaria y la desigualdad social. La Tabla 4 ilustra algunas de las diferencias más significativas entre las relaciones de negocio tradicionales y las realizadas en una cadena de valor, que demuestran por qué las primeras han tenido una pobre contribución a la competitividad del sector agropecuario, y por qué las últimas se constituyen en un enfoque estratégico promisorio para el mismo.

Algunas de las ventajas que ofrece el enfoque de cadena de valor es que facilita el desarrollo de alianzas productivas entre los diferentes eslabones, permitiendo el uso más eficiente de los recursos disponibles para alcanzar los objetivos comunes. Acosta (2006) explica que este tipo de acuerdos pueden involucrar intercambio de conocimiento, tecnología, confianza, capacidades, compartir riesgos y beneficios. Entre las diferentes modalidades de alianzas productivas se puede encontrar "alianzas verticales", las cuales ocurren entre los diferentes eslabones de la cadena que van desde la provisión de insumos, pasando por la producción, transformación, comercialización y el transporte, hasta el mercadeo y la distribución; o "alianzas horizontales", que son acuerdos o fusiones entre empresas del mismo nivel o formación de asociaciones de productores. El proyecto regional de la FAO "Apoyo a la Promoción y Desarrollo de Alianzas Productivas" (citado por Acosta, 2006) permitió identificar diferentes factores que "Facilitan" y "Obstaculizan" el desarrollo de dichas alianzas, los cuales se presentan en la Tabla 4.

La experiencia ha mostrado que el éxito o fracaso de cualquier intervención para el desarrollo de cadenas productivas agropecuarias depende de los actores y las organizaciones empresariales que participan (CIAT, 2004). A pesar de los beneficios ofrecidos y de las facilidades dadas por el Estado para incentivar formas asociativas, en la gran mayoría de los casos estas iniciativas rurales fracasan, se estancan o son aprovechadas por unos pocos, causando pérdidas y frustraciones al resto de los asociados y, por lo tanto, el rechazo del modelo como estrategia de competitividad. Algunas de las dificultades que con mayor frecuencia se presentan son:

- Desconocimiento y confusión entre los diferentes modelos asociativos: cadenas, clusters, redes, etc.

- Desconfianza entre las partes involucradas.

- Primacía de intereses individuales.

- Visión de corto plazo.

- Baja participación de la industria y del sector comercial.

- Poca articulación de las universidades.

- Alta concentración del diálogo en el tema de precios de materias primas y en los asuntos de coyuntura.

- Incumplimiento de los acuerdos establecidos.

- Poca difusión de los acuerdos.

- Indicadores deficientes.

- Protagonismo y falta de coordinación en los agentes.

- Dificultades para pasar de la estrategia a la acción.

- Poca "gerencia" de los acuerdos (Espinal, 2005).

Sin embargo, como lo expresan Vélez \& Campos (2007), estos fracasos deben servir como punto de partida para un análisis serio de la asociatividad rural en cadenas productivas agropecuarias, la cual debe darse no por la exoneración tributaria y la dádiva estatal, sino por la rentabilidad productiva y la capacidad de lucro del organismo y sus asociados, con el objeto de congregar verdaderos esfuerzos económicos y en especie que deriven, en el tiempo, en organizaciones empresariales rentables, autónomas y eficientes. Si no se genera un sistema asociativo enfocado en el desarrollo, más que en la subsistencia, se estará renunciando a las oportunidades que los diferentes procesos comerciales internacionales, en negociación o en curso, representan para el sector agropecuario y el sector se seguirá mostrando débil, pobre, sin capacidad de desarrollo y marginado de los procesos globales. 
Tabla 3. Comparación entre las relaciones del negocio tradicional y las cadenas de valor ${ }^{7}$

\begin{tabular}{|l|l|l|}
\hline & \multicolumn{1}{|c|}{ ENFOQUE TRADICIONAL } & \multicolumn{1}{c|}{ CADENA DE VALOR } \\
\hline Información Compartida & Escasa o ninguna & Amplia \\
\hline Objetivo Primario & Costo / Precio & Valor Agregado / Calidad \\
\hline Orientación & Commoditie & Producto diferenciado \\
\hline Operación & Desde la oferta & Desde la demanda \\
\hline Estructura de la Organización & Independiente & Interdependiente \\
\hline Filosofía & Auto optimización & Optimización de la Cadena \\
\hline
\end{tabular}

Tabla 4. Factores que facilitan u obstaculizan el desarrollo de alianzas productivas en agrocadenas ${ }^{8}$

\begin{tabular}{|l|l|}
\hline & $\begin{array}{l}\text { Diseminación y acceso a la información sobre el funcionamiento del mercado, entre todos los actores. } \\
\text { Amplia coincidencia sobre el diagnóstico de los problemas y las posibles soluciones. } \\
\text { Expectativas de que los beneficios de construir una alianza estratégica son mayores que sus costos. } \\
\text { Certidumbre sobre la capacidad de los actores involucrados en la alianza, de cumplir con los compromi- } \\
\text { sos que vayan a ser adquiridos. } \\
\text { Capacidad de innovar en la creación de mecanismos para el intercambio de recursos. } \\
\text { Existencia cercana de experiencias con alianzas exitosas. }\end{array}$ \\
\hline $\begin{array}{l}\text { Insuficiencia de proyectos comunes definidos. } \\
\text { Falta de información sobre las oportunidades de negocio. } \\
\text { Carencia de espacios para armonizar intereses. } \\
\text { Líderes no capacitados. } \\
\text { Los mecanismos de negociación no se adaptan a las exigencias de los productores agropecuarios. }\end{array}$
\end{tabular}

Las cadenas productivas agropecuarias son excelentes escenarios para ejercitar valores de convivencia, pluralidad, tolerancia, respeto, equidad y buena fe en las relaciones de negocios, capacidad de negociación, concertación, democracia, interdisciplinariedad, entre otras. Para esto, Kairuz (2005) insiste en la necesidad de modernizar las organizaciones, pero también, en una transformación profunda en la educación, el aprendizaje, y la creación y transferencia de conocimiento.

\section{Aplicación de la metáfora biológica de los consorcios microbianos, en las cadenas productivas agropecuarias}

La propuesta de una metáfora biológica desde los consorcios microbianos constituye una aproximación distinta, que ofrece la posibilidad de considerar el modelo asociativo en cadenas productivas agropecuarias desde una perspectiva de totalidad,

7 Fuente: Peña, Nieto \& Díaz, 2008, 80.

$8 \quad$ Fuente. Adaptado de Acosta, 2006, 7. 
partiendo de los elementos aparentemente aislados extraídos de la microbiología. No es la suma de contenidos parciales de una situación analizada; ella añade a las partes del objeto en estudio algo que solo se puede adquirir en el conjunto, en la singularidad (Ruiz, 2007). La aplicación de esquemas de pensamiento propios de una realidad para comprender otra distinta, pero con vínculos claramente identificados, permite enriquecer la visión y los elementos de análisis necesarios para abordar situaciones complejas, lo cual, a su vez, estimula el desarrollo de ideas que constituyen soluciones innovadoras y diferenciales.

Esta propuesta metafórica busca describir el modelo asociativo como estrategia de competitividad, desde su comparación con transformaciones propias de la naturaleza que los actores de las cadenas productivas agropecuarias conocen y entienden, por su importancia e impacto en el desarrollo de su actividad económica. Su propósito fundamental es influenciar, motivar un cambio en la percepción y en la estructura mental tradicional propia de dichos actores, que estimule la creación de capital social, de espíritu cooperativo y de confianza, demostrando la estabilidad evolutiva, sostenibilidad ecológica y eficiencia del modelo asociativo en la naturaleza (Goldman \& Brown, 2009). Capra (1998) sostiene que para construir y mantener comunidades sociales sostenibles, en las que se puedan satisfacer las necesidades y aspiraciones propias, sin mermar las oportunidades de generaciones venideras, es necesario comprender y aplicar los principios de organización de las comunidades ecológicas (ecosistemas), de modo que se manifiesten, en las sociedades humanas, como principios de educación, empresa y política.

La metáfora de los consorcios microbianos que aquí se presenta, constituye una propuesta conceptual, una presentación pedagógica con fines ilustrativos, que busca facilitar el entendimiento y comprensión de un objeto de estudio, en este caso, la asociatividad empresarial en cadenas productivas agropecuarias. Esta metodología se considera apropiada ya que, si bien las organizaciones y los microorganismos pueden existir y sobrevivir de manera aislada $e$ independiente, les resulta costoso, ineficiente $e$ insostenible debido a la complejidad y dinámica del entorno que los rodea. En su investigación, Montoya (2010) considera que las empresas integradas se adaptan mucho mejor a los mercados altamente competitivos y que las alternativas biológicas han demostrado que las especies que trabajan conjuntamente, coevolucionan para poder permanecer $y$ desempeñarse con mayor eficiencia. Un ejemplo concreto se obtiene del estudio de los consorcios microbianos, del cual se han podido distinguir rasgos específicos que son afines con características propias de los sistemas sociales: la agrupación y la cooperación como estrategia para asegurar la supervivencia; la estructura del sistema como la manifestación física (fenotipo) de características esenciales (genotipo) para el desarrollo de la estrategia, y la comunicación, adaptación y coevolución como procesos que configuran el sistema, análogos a la cultura organizacional.

Tanto los consorcios microbianos como las cadenas productivas agropecuarias exhiben formas estructurales de tipo Autopoyético y Hologramático. La autopoiesis (del griego Auto, que significa "sí mismo" y Poiesis, "creación") es un patrón de organización propio de los seres vivos. Se trata de una red de procesos de producción (Ilustración 5), en la que la función de cada componente es participar en la producción o transformación de otros componentes de la red; así, toda la red es producida por sus componentes y, a su vez, los produce (Capra, 1998, 116). Este concepto permite ilustrar las cadenas productivas agropecuarias como un todo, gracias a las relaciones de negocio establecidas entre cada uno de los eslabones, quienes, a su vez, existen como unidades productivas autónomas y eficientes, gracias a que reciben y aprovechan los recursos que le proporciona la cadena; éstos, a su vez, se introducen en un nuevo ciclo de transformación el cual continúa la generación de valor, configurando así una propuesta de gestión rentable para todo el sistema. El principio hologramático, "el todo está en las partes" (Ilustración 6), explica y demuestra que el funcionamiento de cada una de las partes constituyentes de un sistema, es idéntico al del sistema completo. En una cadena productiva agropecuaria, cada actor (eslabón, agente externo, etc.) opera internamente mediante relaciones de beneficio mutuo entre sus áreas funcionales, interdependencia, comunicación, 
y retroalimentación, lo cual, en conjunto, configura una estructura diferencial que permite responder a una razón social, y así participar en un encadenamiento productivo.

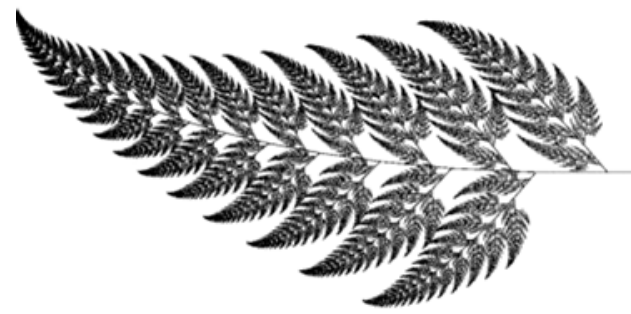

Ilustración 5. Principio hologramático presente en el helecho $^{9}$

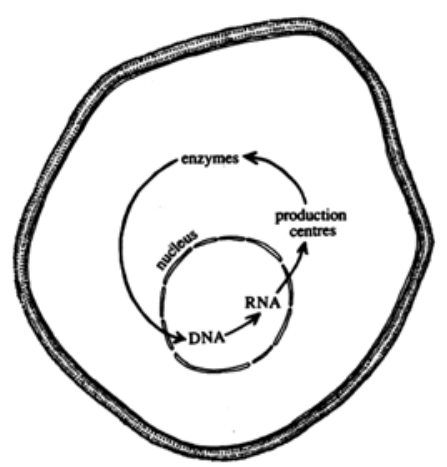

Ilustración 6. Componentes de la red autopoyética responsables de la reparación enzimática del ADN ${ }^{10}$

Las transformaciones mediadas por consorcios microbianos son el resultado de su búsqueda de energía para vivir. Cada participante obtiene este recurso vital efectuando una reacción bioquímica característica y diferencial, sobre un sustrato específico que otro miembro produce, transformándolo a su vez en un producto que alimenta a alguien más en el consorcio. La constante interconexión entre estas reacciones sucesivas es lo que estructura el ciclo (Ilustración 7) produciendo una continua transformación de materia y energía que asegura su supervivencia y equilibrio.

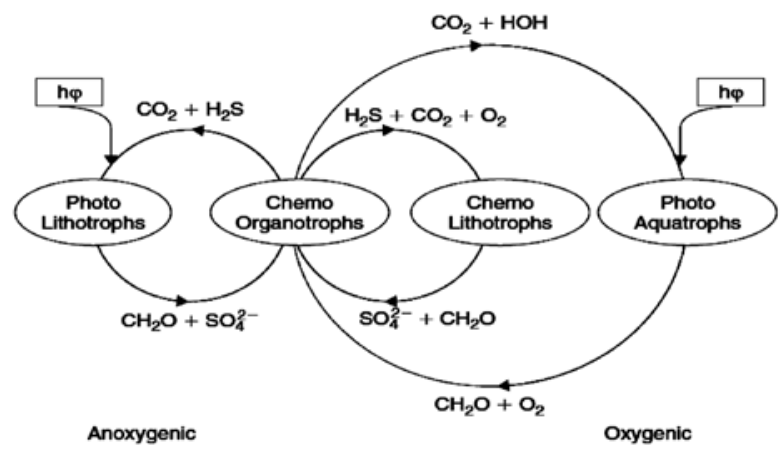

Ilustración 7. Ciclo e Interconexiones ${ }^{11}$

Así como la actividad metabólica continua, compleja y altamente organizada, permite a los microorganismos de un consorcio transformar y asimilar los nutrientes, sintetizar estructuras básicas y liberar productos al entorno, cada unidad constitutiva de una cadena productiva agropecuaria cuenta con un amplio paquete de conocimientos, habilidades y experiencias que le permiten enfocar su actividad en la ejecución de un proceso diferencial, que no solo le provee recursos para alimentarse, sino que le permite crecer, expandirse y entregar al sistema un bien y/o un servicio de valor, susceptible de ser sometido a nuevas transformaciones $y$, por lo tanto, de beneficiar a otros actores. Las ganancias de cada eslabón y de la cadena en general, dependen tanto del desempeño individual como de la capacidad relacional desarrollada, ya que es la transformación sucesiva de una materia prima, realizada en diferentes etapas, por diferentes actores, que invierten esfuerzos, recursos y añaden valor en dicho proceso, lo que las produce. Tal como ocurre en los consorcios microbianos, el objetivo fundamental de esta secuencia es hacer que un bien o un servicio estén disponibles para un cliente, en una forma que le sea provechosa y le ofrezca el máximo beneficio, a cambio de un recurso vital, de tipo económico por ejemplo, que nutre a cada eslabón e impulsa la continuidad de la cadena en general.

Fotografía aportada por los autores.

10 Fotografía aportada por los autores.

11 Fuente: McGill W. B., 2007, 252. 
En una cadena productiva agropecuaria la disponibilidad fluctuante de los recursos económicos (abundancia-escasez), la falta de información y la concentración del poder, entre otras, son circunstancias limitantes que estropean las relaciones de confianza y la credibilidad en el modelo asociativo, creando frustración entre los miembros y el fracaso del proyecto. Es por eso que la cadena, al igual que los consorcios, requieren controles homeostáticos; esto es, la capacidad de desplegar un esquema de autorregulación que permita mantener su estabilidad. El monitoreo constante y cercano puede constituirse en una herramienta capaz de reconocer desequilibrios peligrosos en la cadena; y las acciones correctivas y preventivas, correctamente formuladas y aplicadas, tienen potencial para regresarla al rumbo previamente definido, es decir, a la plataforma estratégica establecida. Sólo en ese equilibrio vital, es que se hace manifiesta una de las principales ventajas de la asociación, tanto en los sistemas biológicos como en los sociales: la disminución de la carga energética que implica una transformación de múltiples pasos. Los costos de transacción, definidos como aquellos en los que se incurre al llevar a cabo una transferencia o intercambio de bienes o servicios, en las diferentes fases técnicamente separables del proceso, pueden compartirse y reducirse significativamente bajo el modelo de encadenamientos productivos, gracias a la integración, la división del trabajo y a la especialización de los actores según sus ventajas comparativas, las cuales incrementan el nivel de coordinación, confianza e intercambio de información, asegurando la consecución de objetivos de mutuo beneficio.

De la misma forma como los microorganismos en un consorcio desarrollan mecanismos que les permiten sobrevivir ante condiciones ambientales extremas, cambiantes y subóptimas, los actores participantes de un encadenamiento productivo agropecuario pueden, ante una perturbación significativa en su entorno, cambiar su estructura, modificar su constitución o incluso re-definirse y/o re-inventarse como empresa, a través de procesos de innovación y aprendizaje colectivo. Esto, a su vez, puede impactar a toda la cadena en la medida en que se compartan las experiencias y enseñanzas, dentro de un marco colaborativo que demanda responsabili- dad en el manejo de la información. Los cambios genéticos heredables o mutaciones que ocurren entre microorganismos cumplen el propósito de conservar, compartir y multiplicar habilidades metabólicas diferenciales y ventajosas para la resistencia y supervivencia en ambientes cambiantes. Drucker (1999) señala que el conocimiento es probablemente la fuente más importante, si no la única, de ventajas competitivas. El conocimiento, al contrario de lo que solía pensarse, no es un bien libre al cual se pueda acceder a bajo costo. Suele concentrarse en empresas o individuos pequeños y puede comprarse o compartirse (cederse). Los intercambios de conocimiento se favorecen cuando hay cierto nivel de confianza; así los contratos pueden ser más simples y las transacciones más fluidas.

"A medida que florece la asociación, cada parte comprende mejor las necesidades de las demás. En una verdadera asociación, todos los miembros aprenden y cambian: coevolucionan" (Capra, 1998, 311).

La complejidad de los consorcios microbianos es consecuencia de su biodiversidad; una comunidad ecológica diversa es una comunidad resistente. En las cadenas productivas agropecuarias la diversidad cultural y étnica puede representar el mismo papel; diversidad significa distintos tipos de relaciones, distintos modos de enfrentarse al mismo problema. Capra (1998) explica que si la comunidad humana se halla fragmentada en grupos e individuos aislados, la diversidad puede fácilmente convertirse en una fuente de prejuicios y fricciones, pero si se acepta la interdependencia de todos los miembros, la diversidad enriquecerá las relaciones y en consecuencia a la comunidad entera. Aunque se han demostrado situaciones conflictivas en relaciones simbióticas entre microorganismos y entre estos y las plantas, no son una constante dentro del sistema natural; cualquier fluctuación estimulará un proceso adaptativo y coevolutivo que elimine la condición de estrés y mantenga el equilibrio vital. Los mecanismos para reforzar la cooperación como el castigo o las sanciones, pueden conducir a que los participantes tengan un mejor desempeño directo; sin embargo, ésta situación dificulta bastante la medición del costo 
y el beneficio real de la cooperación (West, Griffin, Gardner \& Diggle, 2006). Capra (1998) destaca la necesidad de comprender que ambas partes de un conflicto pueden ser importantes en función del contexto y que las contradicciones en el seno de una comunidad son signos de su diversidad y vitalidad, que contribuyen por lo tanto a la viabilidad del sistema.

La metáfora de los consorcios microbianos sugiere, como elementos mínimos a tener en cuenta para la gestión de los encadenamientos productivos agropecuarios, los siguientes aspectos:

- Sustituir el principio de independencia y competencia, tradicional en la historia empresarial colombiana, para adoptar el de interdependencia y cooperación, que permite la coevolución, reconociendo que todos los miembros de la cadena se hallan interconectados en una vasta $e$ intrincada red de relaciones. El comportamiento de cada eslabón, depende del comportamiento de todos los demás. El éxito de la cadena depende del de sus eslabones, mientras que el éxito de éstos depende del de la cadena como un todo.

- Efectuar un cambio en el manejo de las relaciones de poder, pasando de las estructuras jerárquicas de dominación en las que hay superiores e inferiores, a otra clase más apropiada: el poder como influencia sobre los otros. Su estructura representativa es la organización en red; en ella no hay niveles ni supremacías y cada actor participante recibe la misma importancia y valor que los demás.

- Aprender a pensar de manera sistémica, es decir, quitar el enfoque analítico de las partes constituyentes, los eslabones, los agentes externos, etc., y reconocer que es la totalidad, el contexto y las relaciones, las que definen las características y operación del modelo asociativo. Las propiedades de la cadena no se conocen analizando las partes, emergen de la complejidad de su configuración.

- Aceptar que ninguna de las funciones y/o responsabilidades de ninguna de las partes de la cadena es fundamental. Todas se derivan de las funciones y/o responsabilidades de las demás y es por esa dependencia, necesaria para la supervivencia, que la cadena se constituye y estructura garantizando su éxito y sostenibilidad. El liderazgo no se entiende como una posición de privilegio exclusiva de algún miembro sino como una actitud de cooperación intensiva a lo largo de toda la cadena.

- Adoptar una forma nueva y diferente de comunicación, entendida no como la transmisión de información entre los diversos agentes de la cadena, sino como una coordinación de comportamientos mediante interacciones o acoplamientos mutuos (Maturana, 2008). Es decir, no se trata de una actividad inofensiva que no provoca ninguna reacción; todo lo contrario. La comunicación debe ser un intercambio de información, señales, bienes o servicios, dotado de algún significado, que estimule un comportamiento de beneficio mutuo. Es importante señalar que la información estratégica debe fluir por todo el sistema y ser ampliamente conocida, pero la información especializada debe ser filtrada y enfocada a los actores de la cadena que la requieran. No es eficiente sobrecargar a las partes de información que deben administrar y replicar, lo cual implica una inversión de recursos y esfuerzos, cuando ésta no les ofrece ningún aporte para la consecución de sus objetivos específicos.

- Reconocer la importancia del cumplimiento y ejecución fluida de las relaciones, compromisos y acuerdos establecidos al interior de la cadena. Para ello resulta conveniente "imitar" la operación de los consorcios microbianos; cada una de las partes debe asumir responsablemente la asignación que le corresponda, ya que es su aporte distintivo y exclusivo, tanto para la propia supervivencia como para la sostenibilidad y eficacia del modelo como estrategia de competitividad.

- Reemplazar los actuales sistemas industriales lineales, los cuales absorben recursos, los transforman en productos y desperdicios, contami- 
nan el ambiente con los desperdicios y venden los productos a los consumidores que, a su vez, producirán más desperdicios al usarlos. Para ser sostenibles, los patrones de producción y consumo deben ser cíclicos, tal como ocurre en los consorcios microbianos; el sistema como un todo no produce desperdicios porque lo que es residuo para un agente, es alimento para otro. El esquema asociativo exige que cada actor entienda que no puede funcionar como una unidad aislada multipropósito, sino que, en el medio en que se desarrolla, alguien lo sostiene y debe sustentar a alguien más (Pauli, 2010).

Las cadenas productivas agropecuarias son un esquema de gestión y una estrategia de competitividad, que hacen parte de un sistema mayor, el cual ejerce gran influencia sobre su crecimiento, desarrollo, expansión y alcance. Tal sistema corresponde a las estructuras básicas de organización jurídica, política y económica de un país, las cuales deben propiciar un entorno empresarial sustentador del esfuerzo colectivo, que conduzca a un desarrollo más acelerado de ventajas competitivas sostenibles (Esser, et $\mathrm{al}, 1996)$. Es importante destacar que quienes compiten ya no son solamente las compañías sino los Sistemas de Producción Territorial, en función del desarrollo económico local, como proceso en el cual los gobiernos, las comunidades y el sector privado, con apoyo de la academia, trabajan juntos para manejar recursos existentes, generar empleo y estimular la economía en un territorio definido (Ceballos, 2008). De esta forma, un encadenamiento productivo agropecuario será exitoso siempre que la compatibilidad de la actividad económica y la capacidad relacional desarrollada, permitan que los eslabones coexistan cercanamente y se extiendan incluso territorialmente.

Puede darse, en muchas ocasiones, que uno de los actores de la cadena que no es muy activo en condiciones normales, llega a ser el eje principal en cuanto se requiera. Este puede ser el caso de un minorista que apoye la cadena en momentos de escasez; el gobierno que, a través de seguros especializados, permita superar una situación adversa que haya arrojado pérdidas en la producción agropecuaria; o el aporte de una entidad educativa, que facilite el desarrollo de una innovación tecnológica para impulsar su desempeño en los mercados. De esta forma y así como en los consorcios microbianos, un agente que se consideraba fuera del escenario puede permitir la supervivencia del grupo en general. Un encadenamiento productivo agropecuario puede afrontar escenarios complejos y cumplir objetivos de gran envergadura, propios en las nuevas dinámicas de mercado, que las unidades productivas aisladas no. La interdisciplinariedad, la especialización y la división del trabajo no solo enriquecen y diversifican la operación del encadenamiento, sino que proporcionan solidez y estabilidad a cada una de las partes constituyentes, permitiéndoles tratar con las contrariedades y oportunidades del entorno.

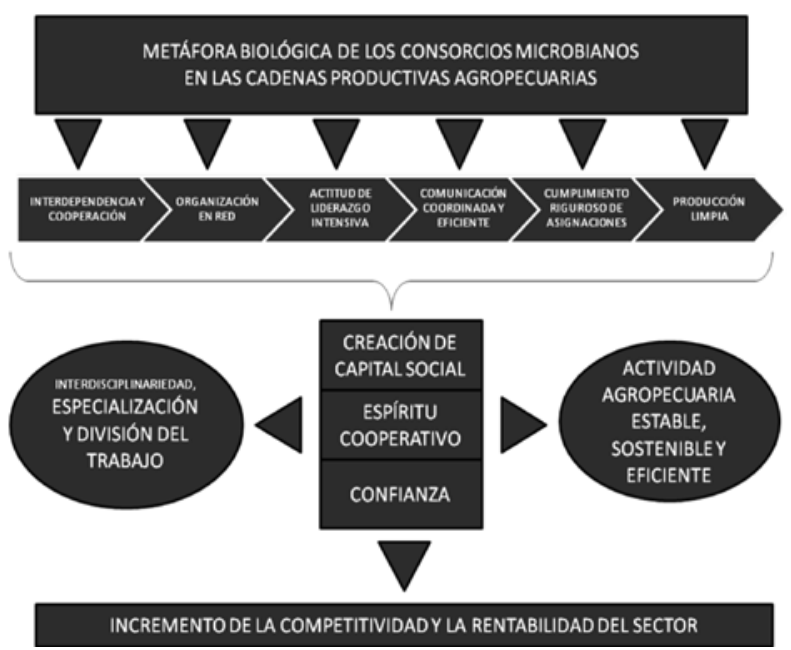

Ilustración 8. Presentación gráfica de la propuesta de la metáfora biológica de los consorcios microbianos, en las cadenas productivas agropecuarias ${ }^{12}$

Como todas las demás metáforas biológicas, la de los consorcios microbianos presenta limitaciones importantes, especialmente porque no permite explorar la operación de las cadenas productivas agropecuarias, bajo escenarios diversos y complejos como los generados cuando se hace evidente el carácter tremendamente variable y libremente articulado de los sistemas sociales. Aunque alienta

12 Las autoras. 
a reconocer que es posible una unidad y armonía en el esquema asociativo, desconoce el efecto de las manifestaciones sicológicas de los actores. Las cadenas productivas agropecuarias son producto de muchas ideas, visiones, normas y creencias, por lo que su forma y estructura es mucho más frágil que la de los consorcios microbianos.

\section{Conclusiones}

Comprender un objeto de estudio es el punto de partida para intervenir sobre él. La metáfora, como una alternativa metodológica que permite construir nuevos desarrollos conceptuales, ofrece la posibilidad de enriquecer el conocimiento y los análisis de la realidad circundante, gracias a la aplicación de esquemas de pensamiento propios de una ciencia, sobre otra distinta, en virtud de rasgos comunes característicos. La metáfora biológica, con sus bondades y limitaciones, proporciona una nueva visión de las organizaciones sociales, por cuanto las describe e interpreta a la luz del sistema de la naturaleza.

El artículo exploró los consorcios microbianos, como organizaciones vitales para el equilibrio del ecosistema, que han existido y evolucionado a lo largo de millones de años gracias a su estrategia de supervivencia y operación, la cual ha demostrado ser sostenible, estable y eficiente: la asociación. Esta misma estrategia es la que hoy por hoy se requiere y promueve intensivamente en el contexto empresarial nacional, debido a la consolidación de un nuevo orden económico mundial y a los profundos cambios en los flujos comerciales.

La opción de conformar cadenas productivas agropecuarias, como estrategia de competitividad, supone la adopción de un enfoque generador de valor, en el que las partes involucradas desarrollen relaciones asociativas, de mutuo beneficio, en función de objetivos comunes. La metáfora de los consorcios microbianos ofrece una nueva perspectiva de este modelo, construida sobre la base de principios sistémicos como las relaciones de interdependencia, la estructura de red, la comunicación coordinada, el cumplimiento responsable y riguroso de acuerdos y responsabilidades asignadas, la especialización y división del trabajo, la producción cíclica y amigable con el medio ambiente, el aprendizaje colectivo, la innovación, entre otros. El propósito de esta metáfora es hacer un aporte conceptual que estimule el restablecimiento de la confianza y credibilidad en el modelo, demostrando su viabilidad y conveniencia para el desarrollo de ventajas competitivas sostenibles en el sector agropecuario.

La biología de los consorcios microbianos ofrece la posibilidad de entender como la asociación y la división de las tareas dentro de un sistema social permiten, a partir de la especialización, el desarrollo de proyectos que de manera autónoma no se podrían lograr; a partir de estos mecanismos de cooperación, coevolución y de compartir recursos para adaptarse en ambientes extremos, han logrado mantenerse por millones de años y sobrevivir. Las cadenas productivas agropecuarias enfrentan las mismas dificultades: escasez de recursos, entornos adversos, información desagregada, etc.; la alternativa que presenta el enfoque biológico resulta de gran interés porque enseña cómo, a partir de estas reglas básicas y sencillas, se puede evolucionar y ser más competitivo.

\section{Referencias}

Acosta, A. (2006). Agrocadenas de Valor y Alianzas Productivas: Herramientas de apoyo a la agricultura familiar en el contexto de la globalización. Santiago de Chile: Oficina Regional de la FAO para América Latina.

Ahumada, F. (2002). El aprendizaje organizacional desde una perspectiva evolutiva y constructivista de la organización. En: Psicología, XI (001): 139-148.

Albano, S. (2006). Wittgenstein y el Lenguaje. Buenos Aires: Quadrata.

Boquera, M. (2005). Las metáforas en textos de ingeniería civil: estudio contrastivo español-inglés. Tesis Doctoral. Facultad de Filología. Departamento de Teoría de los Lenguajes. Universidad de Valencia, España.

Brenner, K, You, L \& Arnold, F. (2008). Engineering Microbial Consortia: a new frontier in synthetic biology. En: Trends in Biotechnology, 26 (9): 483-489.

Cabello, A. (2000). Teoría de la organización, conocimiento metafórico y universidad. En: Denarius, 2 (1): 167-183.

Capra, F. (1998). La Trama de la Vida. Barcelona: Anagrama.

Carrillo, E. (2003). Analogía y metáfora en el análisis organizacional. Un ejemplo: la organización como cárcel. En: Revista Colombiana de Psicología, 012: 108-113.

Ceballos, M. (2008). Las cadenas productivas como instrumentos para fortalecer la gobernabilidad. Programa Colombia Universidad de Georgetown. Bogotá DC: Ministerio de Comercio, Industria y Turismo. 
Centro Internacional de Agricultura Tropical CIAT. (2004). Gestores de Innovación en Agroindustria Rural; una Alianza para la Innovación en Cadenas Productivas (1 ${ }^{\mathrm{a}}$ Ed.). Palmira: John Jairo Hurtado, Erika Mosquera y Carlos Chilito.

Centro Nacional de Tecnología Agropecuaria y Forestal CENTA. (2002). Asociatividad para mejorar el negocio agrícola. San Salvador: Proyecto CENTA - FAO- Holanda.

Drucker, P. (1999). La Sociedad Poscapitalista. Buenos Aires: Sudamericana.

Escobar, C. (2009).Ecología Microbiana. Obtenido el 15 de septiembre de 2010 desde vanguardia.udea.edu.co/cursos/.../ ECO.\%20\%20MICROBIANA.ppt

Espinal, C. (2005). Cadenas Productivas: experiencias y estrategias para el desarrollo de la competitividad en Colombia. En: Valencia, R. y Muñoz, P. (Compiladores). Asociatividad Empresarial en Colombia. Líderes Promotores de Asociatividad Empresarial. Cámara de Comercio de Bogotá.

Esser, K, Hillebrand, W, Messner, D \& Meyer, J. (1996). Competitividad Sistémica: nuevo desafío para las empresas y la política. En: Revista de la Cepal, 59: 39-52.

García, E \& Toledo, M. (2008). Evaluación de sistemas socioecológicos en áreas protegidas: un instrumento desde la economía ecológica. En: Argumentos, 21 (58): 103-116.

Germinia, (2010). Nutrición de las Plantas. Extraído el 21 de septiembre de 2010 desde http://www.germinia.cl/index2. php?option $=$ com_content\&do_pdf $=1 \& i d=113$

Goldman, R. \& Brown, P. (2009). Making Sense of Microbial Consortia using Ecology and Evolution. En: Trends in Biotechnology, 27 (1): 3-4.

González, M. \& Llinás, E. (2004). La metáfora biológica y la práctica científica. En: Emile Durkheim. Cuaderno Venezolano de Sociología, 13 (3): 367-379.

Guerrero, M, López, A \& Antón, J. (2005). Ecología Microbiana. Ecosistemas, 14 (2), 1-2.

Instituto Colombiano Agropecuario ICA, (2003). Plan Nacional de Protección a la Producción Agropecuaria 2003 - 2006. Bogotá D.C.

Kairuz, V. (2005). La Asociatividad y el Capital Social en Cadenas Productivas en Colombia. En: Valencia, R. y Muñoz, P. (Compiladores). Asociatividad Empresarial en Colombia. Líderes Promotores de Asociatividad Empresarial. Cámara de Comercio de Bogotá.

López, T, Dominguez, L \& García, J. (2007). Arreglo estructural de un consorcio microbiano de interés alimentario en la producción del vinagre. Trabajo presentado en el octavo Congreso Nacional de Microscopía, Octubre, México.

Luo, Y \& Zhou, X. (2006). Soil Respiration and the Environment. Oxford: Elsevier.

Madigan, M, Martinko, J \& Parker, J. (1999). Brock, Biología de los Microorganismos. Madrid: Prentince Hall.

Maier, M, Pepper, I \& Gerba, C. (2009). Environmental Microbiology. San Diego: Academic Press.

Maturana, H. (2008). El árbol del conocimiento. Santiago de Chile: Universitaria.

McGill, W. B. (2007). The Physiology and Biochemistry of Soil Organismsm (Cap. 9). En: Paul, E. (Ed), Soil Microbiology, Ecology and Biochemistry, Oxford: Elsevier.
Ministerio de Comercio, Industria y Turismo. (2007). Política Nacional para la Productividad y Competitividad. Publicación digital de la Biblioteca Luis Angel Arango del Banco de la República. Obtenido el 11 de mayo de 2010 desde http://www. lablaa.org/blaavirtual/ciencias/sena/cursos-decapacitacion/ politicanal/política15.htm

Ministerio de Comercio, Industria y Turismo. (2009). Cadenas, Redes Empresariales y Asociatividad Empresarial. Extraído el 15 de marzo de 2010 desde www.mincomercio.gov.co/ eContent/.../CadenasRedesAsociatividad.pdf

Montoya, A. (1999). Gerencia Genética una nueva perspectiva para la organización. Tesis de grado, Maestría en Administración, Facultad de Ciencias Económicas, Universidad Nacional de Colombia, Bogotá.

Montoya, A. (2010). Gestión de Sistemas de Integración Empresarial desde una perspectiva Biológica. Tesis de grado, Doctorado en Ciencias Económicas, Facultad de Ciencias Económicas, Universidad Nacional de Colombia, Bogotá.

Morgan, G. (1991). Imágenes de la Organización. México: Alfaomega

Morris, S \& Blackwood, C. (2007). The Ecology of Soil Organisms. En: Paul, E. (Ed), Soil Microbiology, Ecology and Biochemistry, Oxford: Elsevier.

Narváez, M, Fernández, G \& Senior, A. (2008). El desarrollo local sobre la base de la asociatividad empresarial: una propuesta estratégica. Opción, 57: 74-92.

Pauli, G. (2010). Zero Waste Communities Strategy. Disponible en: http://www.crra.com/grc/articles/zwc.html.

Peña, Y, Nieto, A \& Díaz, F. (2008). Cadenas de Valor: un enfoque para las Agrocadenas. En: Equidad y Desarrollo, 009: $77-85$.

Plante, F. (2007). Soil Biogeochemical Cycling of Inorganic Nutrients and Metals (Cap. 15). En: Paul, E. (Ed), Soil Microbiology, Ecology and Biochemistry, Oxford: Elsevier.

Ramírez, H. (2006). La Metáfora, un encuentro entre lenguaje, pensamiento y experiencia. En: Boletín de Lingüística, 025: 100-120.

Rammel, C, Stagl, S. \& Wilfing, H. (2007). Managing Complex Adaptative Systems - A co-evolutionary perspective on natural resource managing. En: Ecological Economics, 63: 9-21.

Real Academia Española. (2010). Diccionario de la Lengua Española. Consultado el 01 de abril de 2010 desde http://buscon. rae.es/drael/SrvltConsulta?TIPO_BUS $=3 \&$ LEMA = metáfora

Ruiz, R. (2007). Historia y Evolución del Pensamiento Científico. México: Edición Electrónica Gratuita Eumed.net.

Valencia, R. \& Muñoz, P. (2005). Asociatividad Empresarial en Colombia. Líderes Promotores de Asociatividad Empresarial. Bogotá: Cámara de Comercio.

Vélez, A \& Campos, A. (2007). Hacia la modernización y la consolidación de la asociatividad agropecuaria empresarial en Colombia. En: Revista Nacional de Agricultura, 950: 7-14.

West, S, Griffin, A, Gardner, A \& Diggle, S. (2006). Social Evolution Theory for Microorganisms. En: Nature Reviews of Microbiology, 4: $597-607$. 